\title{
Research in Androgenic Anabolic Steroid Abuse
}

\section{Sculthorpe $\mathbf{N}^{*}$}

Institute for Sport and Physical Activity Research (ISPAR), University of Bedfordshire, Bedford, UK

Since their development in the late 1950's androgenic anabolic steroids (AAS) have generally been considered the drug of choice for many aspiring athletes [1]. Indeed in the decades that have followed, rates of AAS abuse have increased and unlike other performance enhancing drugs, AAS have become widely used outside of professional athletic performance [2]. Thus, while blood doping, for example, is an effective technique to improve performance, its use outside of high level sports performance is relatively rare. On the other hand AAS are used both at high and amateur level as well as by individuals with no intentions of undertaking any structured athletic endeavor. In tandem with this increased prevalence of AAS use was an increase in the amount of published research, with more AAS research published in the last 20 years than was published in total during the preceding years (see figure 1). Much of the research in the 1960's related to the therapeutic potential of testosterones following its discovery and isolation. Since then, most research has focused on the potential negative side effects of AAS abuse and much good work has been done in this area with adverse blood lipid profile, poor cardiac function and endothelial functional parameters amongst the side effects that have the most compelling evidence [3-5].

Of the available research, there are broadly speaking, 2 methods of investigation. Firstly there are those that have examined the effect of a relatively small dose of a known steroid, with known potency and pharmacological quality on a cohort of volunteers. While the second type relies on recruiting volunteers who are already self-administering large doses of illicitly acquired AAS. Researchers have always accepted the traditional limitations of each method. The first suffers from low ecological validity as the dose and duration of AAS use may not match (and is typically much lower) that seen in the abuse setting. The latter suffers from low quality control as the type potency and dose of AAS used may vary widely between participants.

However, the usefulness of the latter method is becoming less and less obvious. From the 1950's through to the early 1980's AAS represented the only drugs that where routinely abused by those wishing to increase strength and power. Correspondingly, where researchers recruited selfadministering participants, they were likely to be only abusing AAS. Therefore, where side effects where noted, they were more likely to be attributable to AAS.

Since the 1980's to present there has been a rapid development in the research that examines the mechanisms of skeletal muscle development

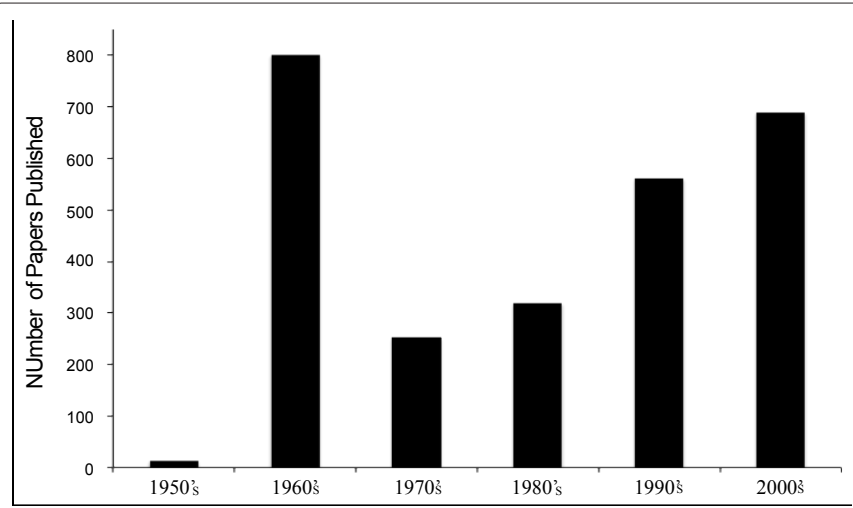

Figure 1: Androgenic anabolic steroid research output by decade. and the role of both local and systemic signaling molecules. Insulin, recombinant human growth hormone (rhGH) and insulin like growth factor I (IGFI) have all been associated with increasing muscle mass [6]. In addition to this, anti-estrogenic agents (e.g. tamoxifen, selective estrogen receptor modulators (SERMs)) are co-abused in an attempt to limit potential side effects, as are anorectic agents (e.g. clenbuterol, ephedrine, triiodothyronine (T3) and dinitrophenols (DNP)) in an attempt to limit or reduce total body fat mass [1]. Finally there is now a significant body of evidence that suggests that co-abuse of other recreational drugs (e.g. amphetamine, cocaine etc) is more prevalent in use of AAS than in the general population [7].

This is of significance for those engaged in research that relies on recruiting self-administering participants. The increased options available to strength and power athletes (whether they be professional, amateur or recreational) has reduced the likelihood of recruit participants who only abuse AAS. Consequently, when a participant presents with poor blood lipids, cardiac dysfunction or adverse liver enzymes, it is very unlikely that AAS are the only drug they are abusing, and thus the root cause is correspondingly more difficult to determine. A further confounding factor is that, the advent of the internet has meant that not only are there more options available to athletes, but it is far easier to acquire AAS and those alternate drugs outlined above (albeit of perhaps dubious authenticity).

Given this background, there is a limit to the options available to researchers. The very least that researchers should do is ask for a list of drugs participants are currently using and have previously used. At least in this way, trends of potential side effects may be more easily attributed to one or other of the performance-enhancing drugs that may be being used. However, in the long run, it is likely that the relative usefulness of studies of self-administering athletes will diminish significantly. In essence, we are moving (or have moved) from a period where AAS abuse was the primary vehicle for increasing muscle mass, to one where poly-drug protocols are the methods of choice. Researchers will have to decide whether to assess the side effects of AAS using the more strictly controlled but less ecologically valid methods, or to assess the effects of abusing multiple drugs with the proviso that the side effects are likely to vary widely depending on the specific profile of drugs being used (Figure 1).

\section{References}

1. Sculthorpe N, Grace F, Angell P, Baker J, George K. (2012) Cardiovascular risk and androgenic anabolic steroids. Br J Card Nurs 7: 266.

2. Evans NA (2004) Current concepts in anabolic-androgenic steroids. Am J Sports Med 32: 534-542.

3. Lane HA, Grace F, Smith JC, Morris K, Cockcroft J (2006) Impaired

*Corresponding author: Sculthorpe N, Institute for Sport and Physical Activity Research (ISPAR), University of Bedfordshire, Bedford, UK, E-mail: nick.sculthorpe@beds.ac.uk

Received June 25, 2012; Accepted June 27, 2012; Published June 29, 2012

Citation: Sculthorpe N (2012) Research in Androgenic Anabolic Steroid Abuse. J Sports Med Doping Stud 2:e114. doi:10.4172/2161-0673.1000e114

Copyright: ( 2012 Sculthorpe N. This is an open-access article distributed under the terms of the Creative Commons Attribution License, which permits unrestricted use, distribution, and reproduction in any medium, provided the original author and source are credited. 
vasoreactivity in bodybuilders using androgenic anabolic steroids. Eur $\mathrm{J}$ Clin Invest 36: 483-488.

4. Achar S, Rostamian A, Narayan SM (2010) Cardiac and metabolic effects of anabolic-androgenic steroid abuse on lipids, blood pressure, left ventricular dimensions, and rhythm. Am J Cardiol 106: 893-901.

5. Baggish AL, Weiner RB, Kanayama G, Hudson JI, Picard MH, et al. (2010) Long-term anabolic- androgenic steroid use is associated with left ventricular dysfunction. Circ Heart Fail 3: 472-476.
6. Graham MR, Evans P, Davies B, Baker JS (2008) AAS, growth hormone and insulin abuse: psychological and neuroendocrine effects. Ther Clin Risk Manag 4: 587-597.

7. Dodge T, Hoagland MF (2011) The use of anabolic androgenic steroids and polypharmacy: A review of the literature. Drug Alcohol Depend 114: 100-109. 